\title{
Shifts of subgingival bacterial population after nonsurgical and pharmacological therapy of localized aggressive periodontitis, followed for 1 year by Ion Torrent PGM platform
}

\author{
Giuseppina Campisciano ${ }^{1,2}$, Annamaria Toschetti ${ }^{3}$, Manola Comar ${ }^{1,2}$, Rosanna Di Taranto ${ }^{3}$, \\ Federico Berton ${ }^{1}$, Claudio Stacchi ${ }^{1}$
}

Correspondence: Dr. Claudio Stacchi

Email: claudio@stacchi.it

\begin{abstract}
'Department of Medical, Surgical and Health Sciences, University of Trieste, Trieste, Italy,

${ }^{2}$ Advanced Diagnostics Department, Institute for Maternal and Child Health, IRCCS "Burlo Garofolo", Trieste, Italy,

${ }^{3}$ Private Practice, Gorizia, Italy
\end{abstract}

\section{ABSTRACT}

The possibility of targeting the hypervariable region V3 of the 16S rRNA gene using Ion Torrent Personal Genome Machine (PGM) could provide a complete analysis of subgingival plaque samples, potentially able to identify microbiological species missed by culture-based methods. A 16-year-old female smoker patient, affected by localized aggressive periodontitis, underwent a full-mouth disinfection protocol and was inserted in a 3-month recall program. Microbiological samples were collected at baseline and at 30, 100, 365 days follow-up and analyzed by Ion Torrent PGM. Capnocytophaga, Fusobacterium, Prevotella, and Treponema were the most represented pathogens at baseline. Nonsurgical treatment and systemic antibiotics drastically lowered the anaerobic species, and their presence remained limited after 100 days, while a consistent recolonization by anaerobic bacteria was detected at 365 days. The patient showed a general improvement of periodontal conditions. Differently from polymerase chain reaction and other microarray techniques, Ion Torrent performs a quantitative analysis of the microbiota, irrespective of the searched species. An accurate definition of the shifts of the bacterial community might help periodontal researchers for a better understanding of the impact of different treatment approaches or in intercepting nonresponsive conditions.

Key words: Anaerobic bacteria, full-mouth disinfection, Ion Torrent Personal Genome Machine, localized aggressive periodontitis, nonsurgical treatment

\section{INTRODUCTION}

Localized and generalized aggressive periodontitis show different clinical features, ${ }^{[1,2]}$ being also characterized by slightly diverse bacterial profiles in the subgingival microbiota. ${ }^{[3,4]}$ The etiology of both diseases is widely thought to be polymicrobial, ${ }^{[5,6]}$

\begin{tabular}{|l|l|}
\hline \multicolumn{3}{|c|}{ Access this article online } \\
\hline Quick Response Code: \\
\hline
\end{tabular}

but the role of individual species and their complex interactions with the host have not been clearly defined yet. The first microbiological analyses

This is an open access article distributed under the terms of the Creative Commons Attribution-NonCommercial-ShareAlike 3.0 License, which allows others to remix, tweak, and build upon the work non-commercially, as long as the author is credited and the new creations are licensed under the identical terms.

For reprints contact: reprints@medknow.com

How to cite this article: Campisciano G, Toschetti A, Comar M,
Taranto RD, Berton F, Stacchi C. Shifts of subgingival bacterial population
after nonsurgical and pharmacological therapy of localized aggressive
periodontitis, followed for 1 year by lon Torrent PGM platform. Eur J Dent
2017;11:126-9.
DOI: $10.4103 /$ ejd.ejd_309_16


on these pathologies were conducted with conventional culture or immunohistochemical methods, ${ }^{[7,8]}$ followed by a generation of molecular detection methods such as hybridization assays or polymerase chain reaction $(\mathrm{PCR})^{[9,10]}$ and even using atomic force microscopy to indagate bacterial morphology and to examine microbial interactions in subgingival biofilm. ${ }^{[11]}$ The most recent advance has been cloning and sequencing of 16S rRNA genes using the fast Ion Torrent Personal Genome Machine (PGM): this approach, up-to-date reported only once in periodontology, ${ }^{[12]}$ allows an open-ended exploration of bacterial populations, potentially revealing the presence of uncultivated species. The possibility of targeting the hypervariable region $\mathrm{V} 3$ of the 16S rRNA gene could provide a complete analysis of subgingival plaque samples, giving additional informations to evaluate the impact of different treatments or to detect the presence of resistant forms of various bacteria species. The aim of the present case report was to follow shifts in subgingival bacterial communities after nonsurgical and pharmacological therapy in a case of localized aggressive periodontitis using next generation $16 \mathrm{~S}$ rRNA gene sequencing approach. ${ }^{[13]}$

\section{CASE REPORT}

A 16-year-old female Caucasian patient, smoker (10 cigarettes/day for 3 years), was referred to our observation showing a localized aggressive form of periodontitis. ${ }^{[14]}$ After retrieving general and dental anamneses, the patient underwent oral examination to assess periodontal conditions and dental health: complete periodontal chart was performed (full-mouth plaque score [FMPS]: 38\%; full-mouth bleeding score [FMBS]: $28 \%$ ), together with full-mouth periapical radiographs. Then, after receiving oral hygiene instructions and motivation, the patient underwent causal therapy according to full-mouth disinfection protocol, ${ }^{[15]}$ together with the following pharmacological therapy: $875 \mathrm{mg}$ amoxicillin $+125 \mathrm{mg}$ clavulanate twice a day and $250 \mathrm{mg}$ metronidazole 3 times a day, for 10 days. ${ }^{[16,17]}$ The patient was reevaluated in 30 days and then recalled every 3 months for supportive periodontal therapy, based on periodontal risk assessment. ${ }^{[18]}$ New periapical radiographs and periodontal chart were collected after 1 year (FMPS: 16\%; FMBS: 1\%). No further pharmacological therapy was prescribed during the entire follow-up period and the patient did not quit smoking. Microbiological samples were collected at baseline and at 30, 100, 365 days follow-up from every pathological site (probing depth [PD] $\geq 5 \mathrm{~mm}$ ).

Supragingival plaque was gently removed; teeth were air-dried and isolated with cotton rolls. A sterile paper point (ISO45, Roeko Dental, Langenau, Germany) was inserted for $10 \mathrm{~s}$ in each site, and all paper points were pooled in a sterile test tube.

\section{Sample processing}

$16 S$ rRNA gene amplification

DNA extraction was performed using the NucliSENS ${ }^{\circledR}$ easyMAG ${ }^{\circledR}$ system (Biomerieux, Gorman, North Carolina, USA). A real-time quantitative EvaGreen ${ }^{\circledR}$ dye (Fisher Molecular Biology, Waltham, Massachusetts, USA) PCR was performed with the degenerated primer 27FYM to better amplify several bacterial species, and the U534R primer, targeting the V1-V3 region of $16 \mathrm{~S}$ gene. A nested PCR was performed with the primers B338F_P1-adaptor (B338F 5'-ACTCCTACGGGAGGCAGC-3') and U534R_A_ barcode (U534R 5'-ATTACCGCGGCTGCTGG-3'), to prepare a 200 base template for final sequencing, with a different barcode for each sample, to amplify the bacterial V3 region. ${ }^{[19]}$

\section{PCR sample processing}

The correct size of the amplicon (260 bp) was assessed on a $2 \%$ agarose gel. Quantification of the amount of DNA was assessed with a Qubit ${ }^{\circledR} 2.0$ Fluorometer (Invitrogen, Carlsbad, California, USA) and an equal quantity of PCR from each sample was used to produce the pooled library.

\section{Ion Torrent sequencing}

The pooled library was diluted at a concentration of $26 \mathrm{pM}$. Template preparation was performed using the Ion PGM Template OT2 200 kit on Ion OneTouch $^{\mathrm{TM}} 2$ System (Life Technologies, Gran Island, New York, USA), after which the enrichment percentage was carried out on $\mathrm{Qubit}^{\circledR} 2.0$ Fluorometer. The templates were sequenced on the Ion PGM ${ }^{\mathrm{TM}}$ System machine, using the Ion PGM sequencing 200 Kit V2 (Life Technologies, New York, USA).

\section{Sequence data analysis}

QIIME 1.8.0 (Knight Lab, Boulder, Colorado, USA) was used to process the sequence data. High quality $(Q>25)$ sequences were demultiplexed and quality filtered using split_libraries_fastq.py with default parameters, except for length parameter $(150 \mathrm{bp})$. Sequences were clustered into operational taxonomic units (OTU) using de novo OTU picking against the Greengenes 
13_8 reference OTU database with a $94 \%$ and $97 \%$ similarity threshold. Alpha diversity was calculated using Shannon metrics. Statistical analysis was performed with SIMPER and ANOSIM tests.

\section{RESULTS}

At baseline, Capnocytophaga, Fusobacterium, Prevotella, and Treponema were the most represented genera in a composite microbiota ( $\alpha$ diversity $=6$ ). Nonsurgical treatment following full-mouth disinfection protocol together with systemic antibiotic therapy drastically lowered the anaerobic species and only a limited presence of Capnocytophaga could be detected at 30 days after treatment $(\alpha$ diversity $=2)$. The recolonization of the pockets by anaerobes started to be evident 100 days after treatment $(\alpha$ diversity $=4)$. Among the detected genera, Porphyromonas, Prevotella, Dialister, Capnocytophaga, and Treponema showed a greater relative abundance at 365 days posttreatment comparing to the microbiota composition at the baseline. Specifically, the presence of Tannerella was restored and Aggregatibacter was lowered;

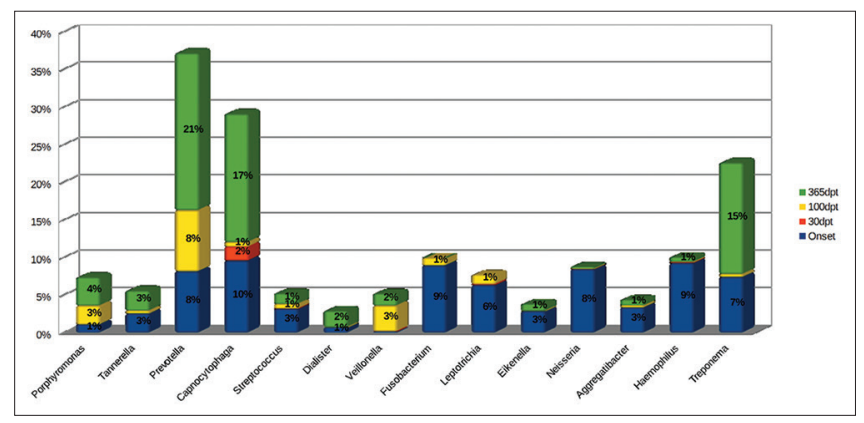

Figure 1: The genus-level composition of the subgingival bacterial population $(\%)$ at the different time points ( $\mathrm{dpt}=$ days posttreatment)
Fusobacterium was not present and Veillonella was detected. Conversely, commensal species such as Streptococcus, Leptotrichia, Eikenella, Neisseria, and Haemophilus were absent or lowered ( $\alpha$ diversity $=5$ ). The observed differences were not statistically significant (assessed by Kruskal-Wallis test).

\section{DISCUSSION}

In the present case [Figure 1], it appears clearly how the subgingival microbiota changed in quantity and quality from pretreatment to posttreatment. As previously reported, ${ }^{[20,21]}$ recontamination of the affected sites was the main issue pushing researchers for developing protocols such as "full-mouth disinfection," in all its updated versions. ${ }^{[15,22,23]}$ Nevertheless, some authors consider the real advantages of this procedure as a questionable and controversial matter. ${ }^{[24,25]}$ In this patient, shifts of subgingival microbiota determined both clinical and radiographical improvement of the periodontal conditions [Figure 2]. FMPS and FMBS decreased along time as well as the probing depth of the pathological pockets. However, the increasing of anaerobic pathogens appeared remarkable at 365 days after treatment, suggesting that the 3-month recall program alone could be not sufficient for maintaining stable periodontal conditions over time. It is interesting to note that the bacterial shift toward a higher prevalence of pathogen species was not accompanied by clinical signs of inflammation: microbiological analysis seems to predict the necessity of further therapies before the clinical scenario becomes evident.

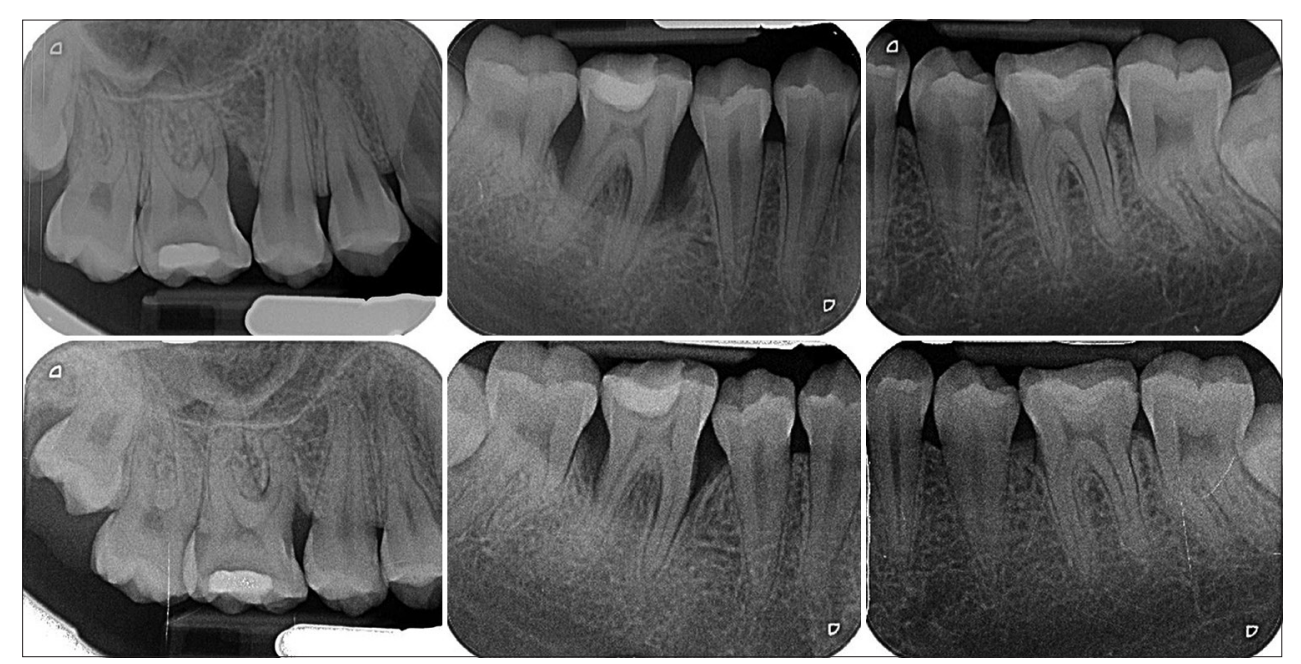

Figure 2: Periapical radiographs comparing baseline condition (upper line) with the situation 1 year after nonsurgical and pharmacological therapy (lower line) 
The main advantage of the Ion Torrent PGM platform is basically due to the high throughput of the technique able to identify microbiological species missed by culture-based method. Differently from PCR and other microarray techniques, Ion Torrent performs a quantitative analysis of the microbiota, irrespective of the searched species. The metagenomic analysis applied in this case report could open possible new perspectives in exploring differences of the subgingival microbiota in periodontal patients: changes in community profiles and metrics could be diagnostically more predictive than the detection of selected periodontal pathogens, such as in PCR or in culture-based methods. An accurate definition of the shifts in the bacterial community could help periodontal researcher for a better understanding of the impact of different treatment approaches or in intercepting nonresponsive conditions.

\section{Financial support and sponsorship}

Nil.

\section{Conflicts of interest}

There are no conflicts of interest.

\section{REFERENCES}

1. Armitage GC, Cullinan MP. Comparison of the clinical features of chronic and aggressive periodontitis. Periodontol 2000 2010;53:12-27.

2. Armitage GC. Comparison of the microbiological features of chronic and aggressive periodontitis. Periodontol 2000 2010;53:70-88.

3. Riep B, Edesi-Neuss L, Claessen F, Skarabis H, Ehmke B, Flemmig TF, et al. Are putative periodontal pathogens reliable diagnostic markers? J Clin Microbiol 2009;47:1705-11.

4. Lang NP, Bartold PM, Cullinan M, Jeffcoat M, Mombelli A, Murakami S, et al. Consensus report: Aggressive periodontitis. Ann Periodontol 1999;4:53.

5. Nishihara T, Koseki T. Microbial etiology of periodontitis. Periodontol 2000 2004;36:14-26.

6. Paster BJ, Boches SK, Galvin JL, Ericson RE, Lau CN, Levanos VA, et al. Bacterial diversity in human subgingival plaque. J Bacteriol 2001;183:3770-83.

7. Saglie FR, Smith CT, Newman MG, Carranza FA Jr., Pertuiset JH, Cheng L, et al. The presence of bacteria in the oral epithelium in periodontal disease. II. Immunohistochemical identification of bacteria. J Periodontol 1986;57:492-500.

8. Christersson LA, Wikesjö UM, Albini B, Zambon JJ, Genco RJ. Tissue localization of Actinobacillus actinomycetemcomitans in human periodontitis. II. Correlation between immunofluorescence and culture techniques. J Periodontol 1987;58:540-5.
9. He T, Hayashi J, Yamamoto M, Ishikawa I. Genotypic characterization of Actinobacillus actinomycetemcomitans isolated from periodontitis patients by arbitrarily primed polymerase chain reaction. J Periodontol 1998;69:69-75.

10. Sanz M, Lau L, Herrera D, Morillo JM, Silva A. Methods of detection of Actinobacillus actinomycetemcomitans, Porphyromonas gingivalis and Tannerella forsythensis in periodontal microbiology, with special emphasis on advanced molecular techniques: A review. J Clin Periodontol 2004;31:1034-47.

11. Germano F, Bramanti E, Arcuri C, Cecchetti F, Cicciù M. Atomic force microscopy of bacteria from periodontal subgingival biofilm: Preliminary study results. Eur J Dent 2013;7:152-8.

12. Jünemann S, Prior K, Szczepanowski R, Harks I, Ehmke B, Goesmann A, et al. Bacterial community shift in treated periodontitis patients revealed by ion torrent $16 \mathrm{~S}$ rRNA gene amplicon sequencing. PLoS One 2012;7:e41606.

13. Milani C, Hevia A, Foroni E, Duranti S, Turroni F, Lugli GA, et al. Assessing the fecal microbiota: An optimized ion torrent 16S rRNA gene-based analysis protocol. PLoS One 2013;8:e68739.

14. Parameter on aggressive periodontitis. American Academy of Periodontology. J Periodontol 2000;71 5 Suppl: 867-9.

15. Quirynen M, Bollen CM, Vandekerckhove BN, Dekeyser C, Papaioannou W, Eyssen H. Full-vs. partial-mouth disinfection in the treatment of periodontal infections: Short-term clinical and microbiological observations. J Dent Res 1995;74:1459-67.

16. van Winkelhoff AJ, Rodenburg JP, Goené RJ, Abbas F, Winkel EG, de Graaff J. Metronidazole plus amoxycillin in the treatment of Actinobacillus actinomycetemcomitans associated periodontitis. J Clin Periodontol 1989;16:128-31.

17. Akincibay H, Orsal SO, Sengün D, Tözüm TF. Systemic administration of doxycycline versus metronidazole plus amoxicillin in the treatment of localized aggressive periodontitis: A clinical and microbiologic study. Quintessence Int 2008;39:e33-9.

18. Lang NP, Tonetti MS. Periodontal risk assessment (PRA) for patients in supportive periodontal therapy (SPT). Oral Health Prev Dent 2003;1:7-16.

19. Sundquist A, Bigdeli S, Jalili R, Druzin ML, Waller S, Pullen KM, et al . Bacterial flora-typing with targeted, chip-based pyrosequencing. BMC Microbiol 2007;7:108.

20. Harper DS, Robinson PJ. Correlation of histometric, microbial, and clinical indicators of periodontal disease status before and after root planing. J Clin Periodontol 1987;14:190-6.

21. Wade WG, Moran J, Morgan JR, Newcombe R, Addy M. The effects of antimicrobial acrylic strips on the subgingival microflora in chronic periodontitis. J Clin Periodontol 1992;19:127-34.

22. Quirynen M, Mongardini C, de Soete M, Pauwels M, Coucke W, van Eldere J, et al. The rôle of chlorhexidine in the one-stage full-mouth disinfection treatment of patients with advanced adult periodontitis. Long-term clinical and microbiological observations. J Clin Periodontol 2000;27:578-89.

23. Keestra JA, Grosjean I, Coucke W, Quirynen M, Teughels W. Non-surgical periodontal therapy with systemic antibiotics in patients with untreated aggressive periodontitis: A systematic review and meta-analysis. J Periodontal Res 2015;50:689-706.

24. Lang NP, Tan WC, Krähenmann MA, Zwahlen M. A systematic review of the effects of full-mouth debridement with and without antiseptics in patients with chronic periodontitis. J Clin Periodontol 2008;35 8 Suppl: 8-21.

25. Eberhard J, Jervøe-Storm PM, Needleman I, Worthington H, Jepsen S. Full-mouth treatment concepts for chronic periodontitis: A systematic review. J Clin Periodontol 2008;35:591-604. 